\title{
Isolation and Characterization of Microsatellites For The Endangered Endemic Tree Nothofagus Alessandrii (Nothofagaceae)
}

Cristian Torres-Díaz ( $\square$ crtorres@ubiobio.cl) Universidad del Bio-Bio - Sede Chillan https://orcid.org/0000-0002-5741-5288

Moisés A. Valladares

Universidad del Bio-Bio - Sede Chillan

Marco A. Molina-Montenegro

Universidad de Talca

Freddy Mora-Poblete

Universidad de Talca

\section{Short Report}

Keywords: Nothofagus alessandrii, Conservation genetics, endangered species, Nothofagaceae, nextgeneration sequencing

Posted Date: February 8th, 2021

DOl: https://doi.org/10.21203/rs.3.rs-168329/v1

License: (c) (i) This work is licensed under a Creative Commons Attribution 4.0 International License. Read Full License

Version of Record: A version of this preprint was published at Molecular Biology Reports on April 24th, 2021. See the published version at https://doi.org/10.1007/s11033-021-06291-3. 
1 Short Communication

2

3 Isolation and characterization of microsatellites for the endangered endemic tree

$4 \quad$ Nothofagus alessandrii (Nothofagaceae)

5

6

7

8 Cristian Torres-Díaz ${ }^{1 *}$, Moisés A. Valladares ${ }^{1}$, Marco A. Molina-Montenegro ${ }^{2,3}$ \& 9 Freddy Mora-Poblete ${ }^{2}$

10

$11{ }^{1}$ Grupo de Investigación en Biodiversidad \& Cambio Global (GIBCG), Departamento 12 de Ciencias Básicas, Universidad del Bío-Bío, Chillán, Región de Ñuble, Chile 13

142 Instituto de Ciencias Biológicas, Universidad de Talca, Avenida Lircay s/n, Talca 153460000 , Chile

16

$17{ }^{3}$ Centro de Estudios Avanzados en Zonas Áridas (CEAZA), Universidad Católica del 18 Norte, Avda. Larrondo 1281, Coquimbo, Chile

19

$20 *$ Corresponding Author: Cristian Torres-Díaz (email: crtorres@ubiobio.cl) 


\section{Abstract}

22 Nothofagus alessandrii (Nothofagaceae) is one of the most endangered trees from

23 Chile. Despite its conservation status, few molecular markers are available to study its 24 population genetic, connectivity and to assist reproduction programs. Novel 25 polymorphic microsatellites from the genome of $N$. alessandrii were isolated and 26 characterized using high-through sequencing. A total of 30 primer pairs were 27 synthesized and 18 microsatellites were amplified correctly. Polymorphism and genetic 28 diversity was evaluated in 58 individuals from three populations of $N$. alessandrii. 29 Sixteen of them were polymorphic and the number of alleles in the pooled sample 30 ranged from 2 to 14 , the mean number of alleles was 4.81 . The mean values of observed 31 heterozigosity $\left(H_{\mathrm{O}}\right)$ and excepted heterozygosity $\left(H_{\mathrm{E}}\right)$ of the Chanco population were 320.392 and 0.383 . The mean values of $H_{\mathrm{O}}$ and $H_{\mathrm{E}}$ in the population of Empedrado $(0.397$ 33 and 0.360, respectively) and Fundo el Desprecio (0.397 and 0.395, respectively) were 34 similar. Linkage disequilibrium was found in a few pairs of loci suggesting that most of 35 the markers can be considered as independent. Significant deviations from Hardy36 Weinberg equilibrium $(P<0.05)$ were found in several loci probably due to low sampling size. Transferability to the congeneric $N$. pumilio was successful in only four out of the sixteen polymorphic markers. The microsatellite markers developed in this study will be useful to study the genetic diversity and structure and to develop integrated managements plans for the conservation on this endangered species.

43 Key Words: Nothofagus alessandrii, Conservation genetics, endangered species,

44 Nothofagaceae, next-generation sequencing 


\section{Introduction}

46 Nothofagus alessandrii (Nothofagaceae), also known as "ruil", is a broad-leaf

47 deciduous tree endemic to the Mediterranean climate zone of central Chile $\left(35-36^{\circ} \mathrm{S}\right)$.

48 The species is among the most primitive species within the genus [1,2] and has been

49 considered as a "living fossil" [3]. The International Union for Conservation of Nature

50 [IUCN] classified N. alessandrii as endangered in 1997 [4], status that is maintained

51 nowadays [5]. Currently, the species is restricted to a narrow latitudinal range $(116 \mathrm{~km})$

52 having a narrow area of occupancy $\left(755 \mathrm{~km}^{2}\right)$. From the last decade of the XIX century,

53 the forest dominated by $N$. alessandrii became increasingly reduced and fragmented.

54 Firstly, the species was over exploited for wood (posts and poles) being afterwards

55 replaced by plantations of wheat, and more recently, by Pinus radiata and Eucalypthus

56 globulus. In addition, in the last decades the species has been threatened by

57 anthropogenic origin forest fires, which have increased their intensity and frequency [6].

58 Consequently, the remnant populations of $N$. alessandrii represent a small and highly

59 fragmented sample of a more extended distribution, where most of its stands are

60 secondary growth from stumps sprouts. In addition to those treats, the species shows

61 low reproductive rates (i.e., low seed production and low seedling survival), which are

62 likely to be the result of inbreeding due reduced population sizes and restricted gene

63 flow caused by anthropogenic deforestation.

64 The aim of this study was to develop new microsatellite markers (simple

65 sequence repeats SSRs) for $N$. alessandrii, using high-through-output Illumina

66 sequencing platform. We also tested cross-amplification in one congener species $(N$.

67 pumilio). These new markers should contribute study the genetic diversity of the species

68 at different scales (i.e., fine-scale within population, within and among populations,

69 landscape scale) and to develop conservation strategies related to molecular ecology

70 studies. 


\section{DNA extraction and genome sequencing}

73 Plant material for investigating the polymorphism in N. alessandrii was collected from

74 three populations: (i) Los Ruiles National Reserve, sector "Chanco" (CHA), (ii) Los 75 Ruiles National Reserve, sector "Empedrado" (EMP) and (iii) Fundo El Desprecio

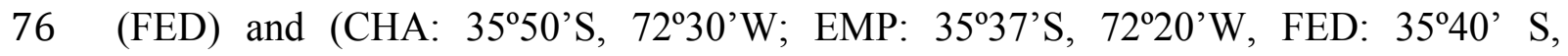
$\left.7772^{\circ} 18^{\prime} \mathrm{W}\right)$. For each population young leafs from adult trees were collected and dried in 78 silica gel before laboratory processing. Tissue from 58 individuals of $N$. alessandrii was 79 collected for DNA extractions ( $n=$ number of individuals; CHA, $n=20$; EMP: $n=20$; 80 FED, $n=18$ ). On each population, a branch of one individuals was taken stored as a voucher in the Herbarium of the University of Concepción, Chillán, Chile (CHA:

82 Voucher specimen No. CONC-CH 6002, EMP: Voucher specimen No. CONC-CH 83 6003, FED: Voucher specimen No. CONC-CH 6001). Additionally, to evaluate crossspecies amplification in $N$. pumilio we used DNA extracted from ten individuals from

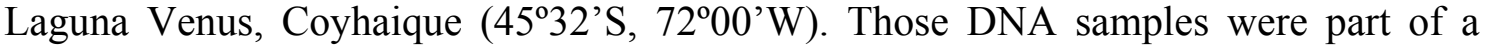
previous research [see reference 7]. In that study, the authors were unable to collect leaf tissue because branch and leafs were not accessible bellow 8-10 meters heights. Hence, DNA had to be extracted from cambium and phloem previously separated from bark, and no herbarium vouchers were taken. Given that $N$. alessandrii is phylogenetically distant to its South American congeners [1, 2], being closer to New Zealand species, we decided to test cross-amplification in $N$. pumilio only as low transferability is the more likely result.

Genomic DNA (gDNA) from both species was extracted using DNeasy Plant mini Kit (Qiagen Valencia, CA, USA) from dried leaves following manufacturer protocol. All the DNA extracts were quantified and standardized using the Qubit ${ }^{\circledR ~} 3.0$ (Invitrogen) fluorometric method. The purified genomic gDNA was normalized to 0.2 $\mathrm{ng} / \mu \mathrm{l}$ and subsequently processed using Nextera ${ }^{\circledR}$ XT DNA library preparation following the manufacturer's instructions. Paired-end high-throughput sequencing was performed on an Illumina HiSeq 2000 platform (Illumina, San Diego, CA, USA) by

100 Australomics Valdivia, Chile (http://australomics.cl). The software QQD version v3.1

101 [8] was used to detect microsatellite motifs on reads higher than $80 \mathrm{pb}$. After this, 102 BLASTn [9] we used to compare all sequences containing repeated motifs with at least $10395 \%$ of similitude. This program identified 2,706 sequences containing short sequence 104 repeats (SSR's) associated to a single group and those that could not be assigned to a 
105 group (singletons). The design of forward and reverse primers was conducted with 106 Primer3 v4.1.0 [10]. A subset of 39 putatively polymorphic SSR's was obtained and a total of 30 primer pairs were synthesized for the subsequent polymorphism screening and genetic diversity estimates. Raw reads for the successfully amplified microsatellites were submitted to National Center for Biotecnology Information (NCBI (Sequence Read Archive (SRA; accession No. MW387624-MW387641, Table 1).

\section{$112 \quad$ PCR analyses and genotyping}

113 For the amplification test, PCRs were performed in a final volume of $10 \mu \mathrm{L}$ containing: 114 PCR, $10 \mu \mathrm{M}$ of fluorescent forward and reverse primers. Forward primers were labeled 115 with PET, FAM, VIC and NED fluorescent dyes (Applied Biosystems) in order to 116 perform capillary sequencing in a genetic analyzer. The amplification protocol was as

117 follows: an initial denaturation step at $95^{\circ} \mathrm{C}$ for $5 \mathrm{~min}, 35$ cycles consisting of a 118 denaturation step at $95^{\circ} \mathrm{C}$ for 30 , specific annealing temperature (Ta) of each primer 119 pair for $30 \mathrm{~s}$ (Table 1), an extension step at $72{ }^{\circ} \mathrm{C}$ for $35 \mathrm{~s}$, followed by a final step of 120 DNA extension at $72^{\circ} \mathrm{C}$ for $7 \mathrm{~min}$. The final PCR products were analyzed on an ABI 121 PRISM 310 Genetic Analyzer with GeneScan 500 LIZ (Applied Biosystems) at the 122 DNA sequencing service of the Pontificia Universidad Católica de Chile (PUC), 123 Santiago de Chile.

124

\section{Microsatellite loci characterization}

126 The software GENALEX v6.1 [11] was used to estimate the number of alleles per locus $127(A)$, the effective number of alleles per population $\left(A_{\mathrm{E}}\right)$, the observed heterozygosity $128\left(H_{\mathrm{O}}\right)$, expected heterozygosity $\left(H_{\mathrm{E}}\right)$, inbreeding coefficient $(F)$ and Hardy-Weinberg 129 equilibrium (HWE) significance. Linkage disequilibrium was tested using GENEPOP 130 version 4.2 [12]. Null allele frequencies were assessed in MICRO-CHECKER v2.2.3

131 [13] using Brookfield's estimator 1 [14]. The statistical significance was assessed using 132 Bonferroni corrected $P$ values.

\section{Results and discussion}

135 A total of 41,144 reads with an average length of 392 bases were obtained from the 136 shotgun sequencing. A total of 2,706 microsatellites were identified in the dataset $(6.5 \%$ 137 of total abundance). Primer pairs were synthesized for 30 out of the 39 putative 138 polymorphic microsatellites. Eighteen microsatellites amplified correctly (Table 1), and 
139 sixteen of them were polymorphic (Table 2), including one tri-nucleotide and fifteen di140 nucleotide repeat markers. Considering all populations, a total of 77 alleles scored. The 141 number of alleles per locus ranged from 2 to 14, with a mean of 4.81 alleles per locus.

142 The mean numbers of effective alleles per locus (AE) were 2.03, 1.78, and 1.99 for $143 \mathrm{CHA}$, EMP and FED, respectively (Table 2). For the entire dataset, the expected $\left(H_{E}\right)$ 144 and observed $\left(H_{\mathrm{O}}\right)$ heterozygosities ranged from 0.000 to 0.856 and from 0.000 to 1451.000 , respectively. The mean $H_{\mathrm{O}}$ and $H_{\mathrm{E}}$ values in CHA population were 0.392 and 1460.383 , respectively. Similar values were found in populations EMP $\left(H_{\mathrm{O}}=0.397, H_{\mathrm{E}}=\right.$ $147 \quad 0.360)$ and $\operatorname{FED}\left(H_{\mathrm{O}}=0.397, H_{\mathrm{E}}=0.395\right)$.

148 Significant deviations $(P<0.05)$ from Hardy-Weinberg equilibrium (HWE) 149 were detected in several loci across populations (Table 2), possibly due to the small 150 sampling size. Null alleles were detected in only three loci from CHA ( $\mathrm{NaO2}, \mathrm{Na12}$, $151 \mathrm{Na16}$ ) and two loci from FED ( $\mathrm{Na11}$, Na12). In general, few loci showed evidence of 152 linkage disequilibrium (LD). Considering the entire dataset only two loci, Na17 and $153 N$ Na28, were significantly linked $\left(\mathrm{Chi}^{2}=17.6, P=0.024\right)$. Within populations, LD was 154 detected between two pairs of loci in CHA (NaO2-NaO9, $P=0.039$; Na04-NaO7, $P=$ 155 0.024) and FED (Na16-Na17, $P=0.042$; Na17-Na28, $P=0.048)$. In EMP population, 156 LD was detected between only one pair of loci $(\mathrm{Na16}-\mathrm{Na28}, \mathrm{P}=0.013)$. Hence, we 157 consider that the microsatellites developed in this study are mostly independent 158 markers.

As predicted, cross-amplification in $N$. pumilio was low, with successful 160 amplification at only four out of the sixteen tested loci ( $\mathrm{NaO4}, \mathrm{NaO9}, \mathrm{Na} 10$ and $\mathrm{Na12}$ ). 161 While NaO4 was monomorphic, NaO9, NaIO and NaI2 had two (150 and 164 bp), two 162 (139 and $142 \mathrm{bp})$ and four (120, 128, 130 and $134 \mathrm{bp})$ alleles, respectively.

To date, only $12 \%\left(0.42 \mathrm{~km}^{2}\right)$ of its distributional range is under protection in 164 the National System of Protected Areas (SNASPE) of Chile [15] and only two 165 populations are considered within these protected areas: Los Ruiles National Reserve 166 Empedrado (EMP) with $0.25 \mathrm{~km}^{2}$ and Chanco (CHA) with $0.45 \mathrm{~km}^{2}$ (both studied 167 here). Consequently, most of the species range of distribution is unprotected but also 168 exposed to an increased frequency of anthropogenic fires. Currently, only one study 169 [16] has addressed the genetic structure of the species but at a very limited extent (only 170 seven fragments) and using allozyme's. Future studies should estimate the amounts of 171 within and among population genetic diversity in the entire distributional range of this 172 endangered species. The 16 markers developed in this study are the first specific 
173 molecular marker developed for N. alessandrii. Those markers can be used to estimate

174 the levels of genetic diversity of the species and to determine its genetic structure at 175 different spatial scales. It is well known that this knowledge is pivotal to understand the 176 evolutionary history of any species but also to develop management strategies aimed to 177 preserve endangered species. For instance, those markers can be used to estimate the 178 current levels gene flow within and among remnant fragments of by performing 179 parentage/paternity analyses. In addition, they could be also used to evaluate whether 180 the poor reproduction and survival currently found in this endangered species is related 181 to anthropogenic habitat fragmentation. Together, these investigations should contribute 182 to design appropriate conservation strategies for this endangered species.

183

184 Acknowledgments

185 This study was supported by the Chilean Agency for Scientific Research and 186 Development (ANID), FONDECYT grant 1181873. All samplings were performed with 187 authorization of CONAF (Chilean forestry service). We also thank to Forestal 188 MININCO (CMPC, Chile) for their valuable help to collect plant material within Fundo 189 el Desprecio”. Dr. Moisés A. Valladares thanks to a Posdoctoral fellowship supported 190 by the Dirección de Posgrado (VRIP) of the University of Bío-Bío, Chillán, Chile.

191

\section{Compliance with ethical standards}

193 Conflict of interest: The authors declare that they have no conflict of interest.

194 Research involving human and animal participants: This article does not contain any 195 studies with human participants or animals performed by any of the authors.

196 Informed consent: This research does not involve humans and therefore informed 197 consents are not applicable. 
199 1. Manos PS (1997) Systematics of Nothofagus (Nothofagaceae) based on rDNA 200 spacer sequences (ITS) - taxonomic congruence with morphology and plastid 201 sequences. Am J of Botany 84:1137-1155. https://doi.org/10.2307/2446156

202 2. Knapp M, Stöckler K, Havell D, Delsuc F, Sebastiani F, Lockhart PJ (2005)

203 Relaxed molecular clock provides evidence for long-distance dispersal of 204 Nothofagus (southern beech). PLoS Biology: e-14.

205 https://doi.org/10.1371/journal.pbio.0030014

206 3. van Stenis CG (1972) Nothofagus, key genus to plant geography. In: Valentine ed. 207 Taxonomy, phylogeography and evolution, 275-288. New York, USA.

208 4. González M (1998) Nothofagus alessandrii. The IUCN Red List of Threatened 209 Species 1998: e.T32033A9676129.

210 http://dx.doi.org/10.2305/IUCN.UK.1998.RLTS.T32033A9676129.en.

211 5. Barstow M, Echeverría C, Baldwin H, Rivers MC (2017) Nothofagus alessandrii.

212 The IUCN Red List of Threatened Species 2017: e.T32033A2808995.

213 http://doi.org/10.2305/IUCN.UK.2017-3.RLTS.T3203 3A280 8995.en

214 6. Echeverría C, Coomes D, Salas J, Rey-Benayas JM Lara A, Newton A (2006)

215 Rapid deforestation and fragmentation of Chilean temperate forests. Biol Cons

216 130:481-494. https://doi.org/10.1016/j.biocon.2006.01.017

217 7. Fajardo A, Torres-Díaz C, Till-Bottraud I (2016) Disturbance and density-

218 dependent processes (competition and facilitation) influence the fine-scale genetic structure of a tree species' population. Ann Bot 117:67-77.

221 8. Meglécz E, Pech N, Gilles A, Dubut V, Hingamp P, Trilles A, Grenier R, Martin https://doi.org/10.1093/aob/mcv148 JF (2014) QDD version 3.1: A user friendly computer program for microsatellite selection and primer design revisited: experimental validation of variables determining genotyping success rate. Mol Ecol Resour 14:1302-1313. https://doi.org/10.1111/1755-0998.12271.

9. Untergasser A, Cutcutache I, Koressaar T, Ye J, Faircloth BC, Remm M and Rozen SG (2012) Primer3 -new capabilities and interfaces. Nucleic Acids Res 40:e115. https://doi.org/10.1093/nar/gks596. Madden TL (2009) BLAST+: architecture and applications. BMC Bioinformatics. 15:10:421. doi:10.1186/1471-2105-10-421. 
232 11. Peakall R, Smouse PE (2006) GenAlEx 6: Genetic analysis in Excel. Population genetic software for teaching and research. Mol Ecol Notes 6:288-295. https://doi.org/10.1111/j.1471-8286.2005.01155.x

235 12. Raymond M., Rousset F (1995) GENEPOP (version 1.2): Population genetic software for exact tests and ecumenicism. J Heredity 86:248-249. https://doi.org/10.1093/oxfordjournals.jhered.a111573

238 13. van Oosterhout C, Hutchinson WF, Willis DPM, Shipley PF (2004) MICROCHECKER Version 2.2.1. Website http://www.microchecker.hull.ac.uk [accessed November 2020]. https://doi.org/10.1111/j.1471-8286.2004.00684.x

14. Brookfield, JFY (1996) A simple new method for estimating null allele frequency from heterozygote deficiency. Mol Ecol 5:4534-4555.

244 15. Bustamante RO, Castor C (1998) The decline of an endangered temperate ecosystem: the ruil (Nothofagus alessandrii) forest in central Chile. Biodiv Cons 7:1607-1626. https://doi.org/10.1023/A:1008856912888

16. Torres-Díaz C, Ruiz E, González F, Fuentes G, Cavieres LA (2007) Genetic diversity in Nothofagus alessandrii (Fagaceae), an endangered endemic tree species of the coastal Maulino forest of central Chile. Ann Bot 100:75-82 https://doi.org/10.1093/aob/mcm07 


\section{Supplementary Files}

This is a list of supplementary files associated with this preprint. Click to download.

- Table1.pdf

- Table2.pdf 